\title{
Comunicação:
}

\section{AVALIAÇÃO DE SEMENTES E PLÂNTULAS DE MILHO UTILIZANDO "SCANNER"1}

\author{
CLEVERSON SILVEIRA BORBA², ANTONIO CARLOS DE OLIVEIRA², DEA ALÉCIA MARTINS NETTO², \\ CLAUDINEI ANDREOLI², RAMIRO VILELA DE ANDRADE ${ }^{2}$ e JOÃO TITO DE AZEVEDO ${ }^{2}$
}

\begin{abstract}
RESUMO - Sementes de milho de 23 lotes de diferentes procedências foram avaliadas quanto ao dano mecânico e germinação através de métodos convencionais e alternativos.Objetivou-se verificar a possibilidade de avaliação pelo método alternativo em monitor de computador e imagens impressas captadas em "scanner" das sementes e plântulas. Os resultados permitiram concluir que a avaliação de sementes danificadas mecanicamente, através do monitor e em papel impresso, proporciona maiores detalhes que nos obtidos no método convencional. A avaliação de plântulas, no monitor e em papel impresso, é viável e reproduz os resultados do método convencional.
\end{abstract}

Termos para indexação: dano mecânico, germinação, Zea mays.

\section{EVALUATION OF SEEDS AND SEEDLINGS OF MAIZE USING "SCANNER"}

\begin{abstract}
Corn seeds of twenty three lots from different sources were evaluated for mechanical damages and germination. Results from conventional and nonconventional methods to evaluate seeds and seedlings were compared. The nonconventional analysis was carried out with a personal computer and a flat bed scanner by evaluating seeds and seedlings using a scanner/monitor and scanner/printout. The results of damaged seeds showed that the evaluation of seeds through scanner/monitor and scanner/printout was more accurate if compared to the conventional method and the evaluation of seedlings in the germination test can be made as an alternative to the currently used method.
\end{abstract}

Index terms: mechanical damage, germination, Zea mays.

\section{INTRODUÇÃO}

O dano mecânico constitui um dos principais problemas que ocorre durante o processo de produção de sementes de milho. A utilização de testes que identificam os danos mecânicos é de suma importância na avaliação das sementes produzidas. Resumidamente, o teste de dano mecânico consiste em mergulhar as sementes em um corante, para que os danos tornem-se mais visíveis e facilitem as avaliações expressas em porcentagem. A seguir, as sementes são classificadas e

aradas em danificadas e não danificadas, sendo utilizado,

alguns casos, a classificação das sementes em diversos graus de danos.

Normalmente, é grande o volume de amostras de sementes que são analisadas nos laboratórios de sementes. Por isso, torna-se conveniente uma simplificação do teste de germinação, sempre que for possivel, para torná-lo mais prático.

No teste de germinação, prescrito pelas Regras para

\footnotetext{
${ }^{1}$ Aceito para publicação em 24.12.96; trabalho financiado pela FAPEMIG (Projeto CAG 710-91).

${ }^{2}$ Pesquisadores do Centro Nacional de Pesquisa de Milho e Sorgo da EMBRAPA. EMBRAPA/CNPMS - C. Postal 151 - CEP 35.701-970 Sete Lagoas, MG, Brasil.

E-mail: borba@cnpms.embrapa.br
}

Análise de Sementes (Brasil, 1992), as sementes de milho são semeadas em substrato próprio e permanecem no germinador por sete dias, quando é feita a primeira contagem das plântulas. Estas são avaliadas individualmente e classificadas como normais, anormais e sementes mortas, e os resultados finais expressos em porcentagens.

Doty et al. (1994) encontraram alta correlação $(\mathrm{R} 2=0,94)$ entre dois métodos de medida de comprimento de raizes de plântulas, um manual e outro através de imagens digitalizadas usando um "scanner" de mesa. Ambos os testes foram efetivos na identificação de bactérias inibidoras do crescimento de plantas, e a medida do comprimento das raízes pelo método do scanner, foi cinco vezes mais rápida que o método manual.

Pan \& Bolton (1991) caracterizando raizes de várias espécies, utilizaram um método alternativo usando um "scanner" de mesa e um microcomputador. Este método eliminou diversas limitações tais como: requerimento para orientação à casualização de amostras do método de interseção de linhas; dependência de confiança em comparações da curva normal dos objetos que não são raizes; e resoluções inadequadas de imagens.

Este trabalho teve como objetivo verificar a viabilidade de avaliação de sementes e plântulas em imagens digitalizadas no monitor de computador e em imagens impressas cap- 
tadas em "scanner".

\section{MATERIAL E MÉTODOS}

O experimento foi realizado no Laboratório de Análise de Sementes do Centro Nacional de Pesquisa de Milho e Sorgo da Empresa Brasileira de Pesquisa Agropecuária EMBRAPA/CNPMS, em Sete Lagoas, MG. Amostras de sementes de 23 lotes de diferentes procedências do milho hibrido duplo BR205 foram analisadas quanto ao grau de dano mecânico e germinação. As avaliações foram realizadas (a)pelo método convencional, (b) em imagens digitalizadas no monitor de computador e (c) em imagens impressas captadas através de um "scanner". Para o método alternativo utilizou-se um computador do tipo PC-486-DX2, $66 \mathrm{MHz}$, um "scanner" de mesa com resolução óptica de 400 pontos por polegada quadrada e uma impressora a jato de tinta, com capacidade de impressão de 720 pontos/polegadas ${ }^{2}$ (Figura 1). Para a avaliação dos danos mecânicos, duas repetições de 100 sementes de cada amostra foram submersas por cinco minutos em $100 \mathrm{ml}$ da solução de iodo a 4,0\% (Marcos Filho et al., 1987). As sementes foram lavadas em água corrente por dois segundos aproximadamente e em seguida secas em condições ambiente. A seguir foram analisadas através dos seguintes métodos: (1) Convencional(\%)determinação de sementes danificadas de forma individual, manual e visual, com o auxílio de uma lupa, em aumento da imagem de cinco vezes; (2) Alternativo via monitor - determinação de sementes danificadas digitalizadas através do "scanner", duas vezes, uma com o lado do embrião e outra com o lado do endosperma voltado para o leitor óptico, e avaliadas diretamente no monitor; (3) Alternativo via impressão - determinação de sementes danificadas e digitalizadas e avaliadas diretamente no papel impresso um com o lado do embrião (Figura 2) e outro com o lado do endosperma (Figura 3) das sementes. As sementes foram consideradas danificadas quando apresentaram um ou mais dos seguintes tipos de danos: semente quebrada, partida, com trincas no embrião ou pequenos estragos superficiais. As mesmas sementes utilizadas nas avaliações dos danos mecânicos foram colocadas para germinar, de acordo com as prescrições das Regras para Análise de Sementes (Brasil, 1992). Após germinadas as plântulas foram avaliadas através dos seguintes métodos: (4) Convencional - avaliação individual, manual e visual; (5) após serem digitalizadas, individual e visualmente, no monitor; (6) após serem digitalizadas, individual e visualmente, no papel impresso (Figura 4). Os dados foram analisados através de uma análise comparativa de médias onde foram determinadas as "distâncias euclidianas" conforme descrito em Morrison (1976) e o "teste t" conforme descrito por Snedecor \& Cochran (1974).
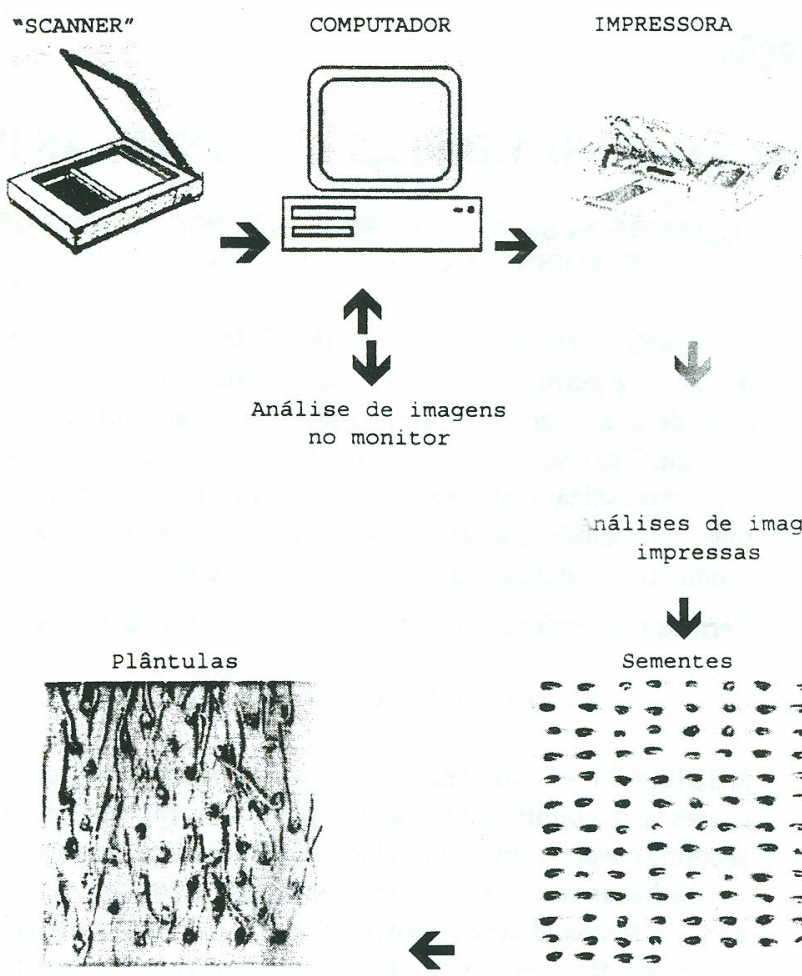

nálises de imagens impressas

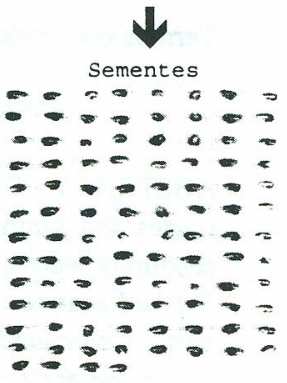

FIG. 1. "Scanner" de mesa, computador e impressora utilizados na geração de imagens das sementes e plântulas no monitor e em imagens impressas.

\section{RESULTADOS E DISCUSSÃO}

Os resultados com as distâncias euclidianas e o teste $t$ das médias estão expressos na Tabela 1. Conforme pode ser observado, para a avaliação de sementes danificadas mecanicamente, as distâncias euclidianas médias $(-1,48$ e -2,11) ocorridas entre a avaliação do método convencional e a av.:liação pelo "scanner"/monitor e entre o método convencional e a avaliação no papel impresso foram pequenas. Os resultados do teste $t$ demonstraram que houve diferença significativa entre os resultados destes testes, evidenciando uma superioridade na deteç̧ão de sementes danificadas pelos métodos de avaliação no monitor e no papel impresso. Estes resultados provavelmente foram devidos ao maior detalhamento visual que estes últimos métodos de avaliação proporcionam.

Para a avaliação de plântulas no teste de germinação, as distâncias euclidianas médias encontradas entre os métodos foram bem pequenas $(-0,53$ e 0,4$)$. Pelo teste $t$ não difere significativamente a $1 \%$ de probabilidade, ficando evidente a equivalência dos métodos, conforme também foi observado por Doty et al. (1994) e Pan \& Bolton (1991), em análises de 


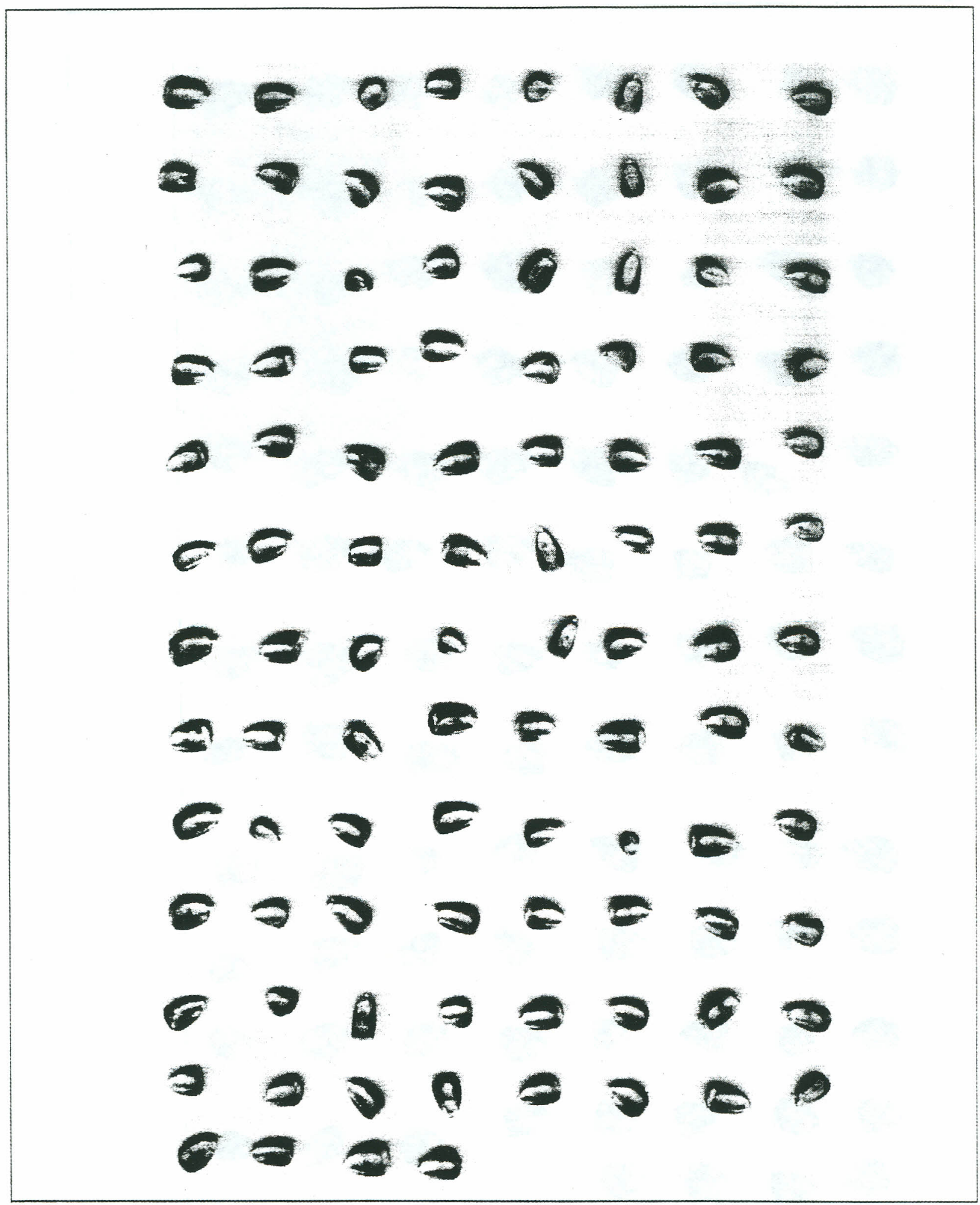

FIG. 2. Imagem impressa de sementes com e sem danos mecânicos.(redução de $30 \%$ do tamanho real) EMBRAPA/CNPMS. Se Lagoas, MG, 1995. 


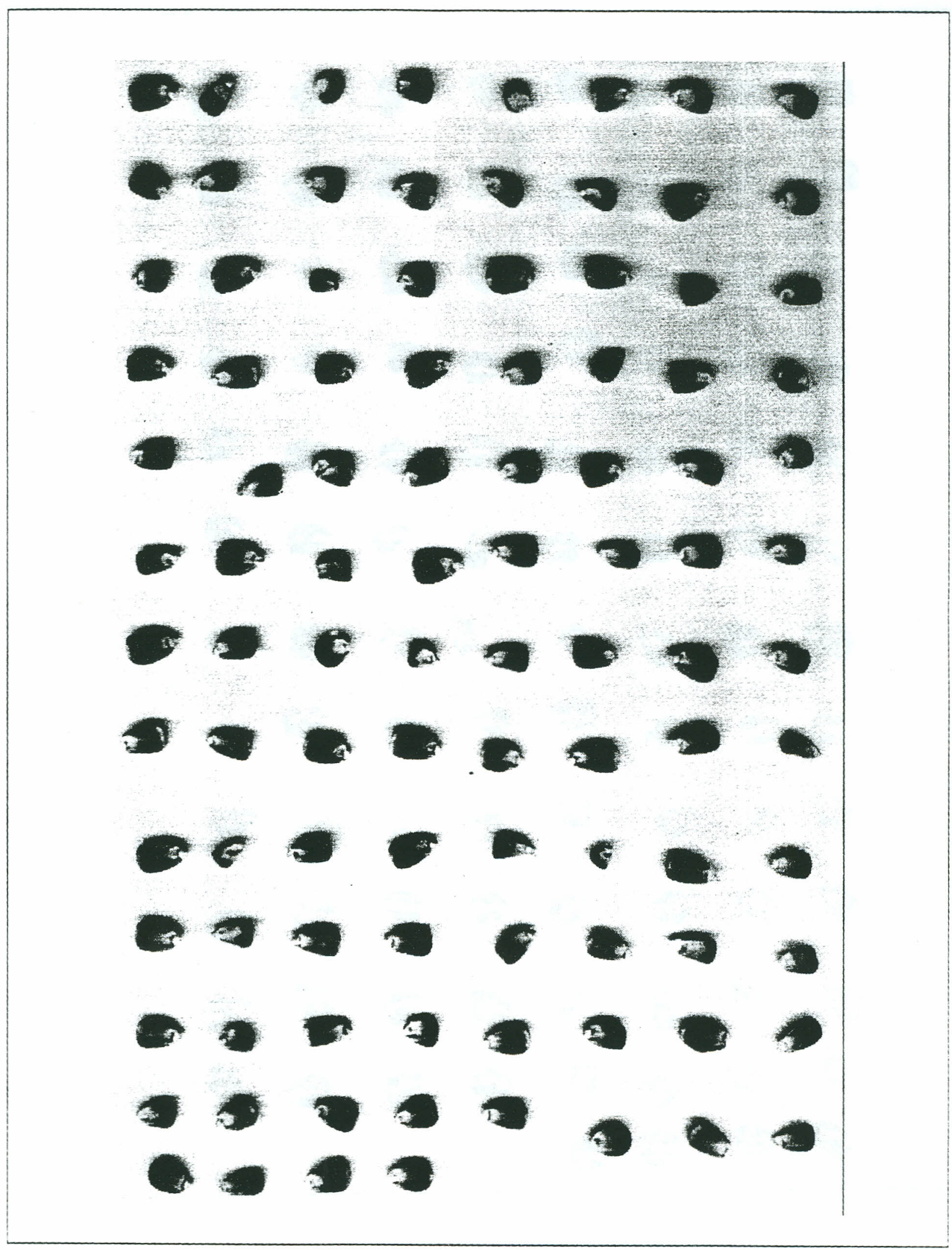

FIG. 3. Imagem impressa de sementes com e sem danos mecânicos. (redução $30 \%$ do tamanho real. EMBRAPA/CNPMS. Se Lagoas, MG, 1995. 


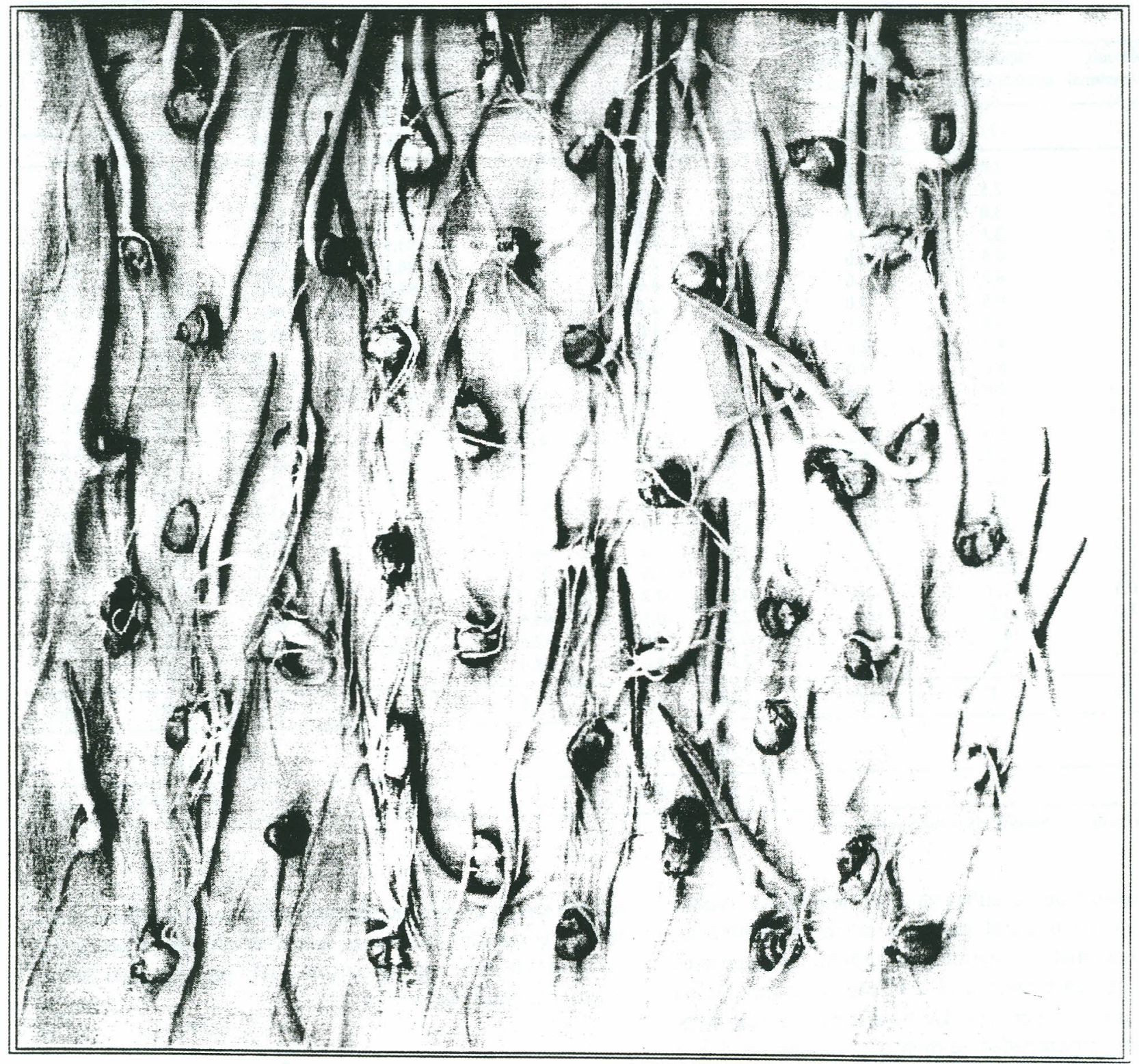

FIG. 4. Imagem impressa de plântulas (redução de 30\% do tamanho real). EMBRAPA/CNPMS. Sete Lagoas, MG, 1995. 
TABELA 1. Danos mecânicos (\%) e plântulas normais (germinação \%) de sementes de milho avaliadas pelos métodos convencional, via scanner/monitor e via scanner/impresso. EMBRAPA/CNPMS. Sete Lagoas, MG, 1995.

\begin{tabular}{|c|c|c|c|c|c|c|c|c|c|c|}
\hline \multirow{3}{*}{$\begin{array}{l}\text { Lotes } \\
\text { de } \\
\text { sementes }\end{array}$} & \multicolumn{3}{|c|}{$\begin{array}{l}\text { Métodos de avaliação de } \\
\text { danos mecânicos }\end{array}$} & \multirow{2}{*}{\multicolumn{2}{|c|}{$\begin{array}{l}\text { Diferenças } \\
\text { entre } \\
\text { métodos }\end{array}$}} & \multicolumn{3}{|c|}{$\begin{array}{l}\text { Métodos de avaliação de plântulas normais } \\
\text { no teste de germinação }\end{array}$} & \multirow{2}{*}{\multicolumn{2}{|c|}{$\begin{array}{l}\text { Diferenças } \\
\text { entre } \\
\text { métodos }\end{array}$}} \\
\hline & \multirow{2}{*}{$\begin{array}{c}\text { Método } \\
\text { convencional } \\
\text { (1) }\end{array}$} & \multirow{2}{*}{$\begin{array}{c}\text { Método via } \\
\text { scanner/monitor } \\
-\cdots(2) \\
\end{array}$} & \multirow{2}{*}{$\begin{array}{c}\text { Método via } \\
\text { scanner/impresso } \\
\text { (3) }\end{array}$} & & & \multirow{2}{*}{$\begin{array}{c}\text { Método } \\
\text { convencional } \\
\text { \% } \\
\text { (4) }\end{array}$} & \multirow{2}{*}{$\begin{array}{c}\text { Método via } \\
\text { scanner/monitor } \\
\text { (5) }\end{array}$} & \multirow{2}{*}{$\begin{array}{c}\text { Método via } \\
\text { scanner/impresso } \\
\text { (6) } \\
\end{array}$} & & \\
\hline & & & & $\mathrm{d}_{1,2}$ & $\mathrm{~d}_{1,3}$ & & & & d..5 & 04.6 \\
\hline 01 & 1,0 & 2,0 & 2,5 & $-1,0$ & $-1,5$ & 97,5 & 97,5 & 97,5 & 0,0 & 0 \\
\hline 02 & 1,5 & 2,5 & 2,5 & $-1,0$ & $-1,0$ & 96,0 & 94,5 & 96,0 & 1,5 & 0 \\
\hline 03 & 1,5 & 3,0 & 4,0 & $-1,5$ & $-2,5$ & 92,0 & 95,5 & 92,0 & $-3,5$ & 0 \\
\hline 04 & 2,0 & 2,5 & 4,0 & $-0,5$ & $-2,0$ & 95,5 & 93,5 & 92,5 & 2,0 & 3,0 \\
\hline 05 & 2,5 & 4,5 & 5,0 & $-2,0$ & $-2,5$ & 96,0 & 96,5 & 96,5 & $-0,5$ & 0,5 \\
\hline 06 & 3,0 & 6,0 & 7,0 & $-3,0$ & $-4,0$ & 97,5 & 95,0 & 95,5 & 2,5 & 2,0 \\
\hline 07 & 4,0 & 9,5 & 7,0 & $-5,5$ & $-3,0$ & 93,5 & 94,0 & 94,5 & $-0,5$ & $-1,0$ \\
\hline 08 & 4,5 & 5,0 & 5,5 & $-0,5$ & $-1,0$ & 93,0 & 93,0 & 93,0 & 0,0 & 0 \\
\hline 09 & 5,0 & 4,5 & 8,0 & $-0,5$ & $-3,0$ & 92,0 & 92,0 & 91,0 & 0,0 & 1,0 \\
\hline 10 & 5,5 & 8,0 & 9,0 & $-2,5$ & $-3,5$ & 93,5 & 95,0 & 95,5 & $-1,5$ & $-2,0$ \\
\hline 11 & 6,0 & 7,0 & 8,0 & $-1,0$ & $-2,0$ & 90,5 & 95.5 & 94,0 & $-5,0$ & 3,5 \\
\hline 12 & 6,0 & 7,0 & 9,0 & $-1,0$ & $-3,0$ & 90,0 & 93,5 & 92,0 & $-3,5$ & $-2,0$ \\
\hline 13 & 6.5 & 8,0 & 10,0 & $-1,5$ & $-3,5$ & 93,5 & 96,7 & 92,5 & $-3,2$ & 1,0 \\
\hline 14 & 6,5 & 8,5 & 8,5 & $-2,0$ & $-2,0$ & 92,5 & 92,0 & 91,3 & 0,5 & 1,2 \\
\hline 15 & 7,0 & 8,0 & 9,0 & $-1,0$ & $-2,0$ & 93,5 & 93,5 & 93,5 & 0,0 & 0 \\
\hline 16 & 7.5 & 7,5 & 9,5 & 0,0 & $-2,0$ & 89,0 & 87,0 & 83,5 & 2,0 & 5,5 \\
\hline 17 & 7,5 & 8,0 & 10,0 & $-0,5$ & $-2,5$ & 91,5 & 92,5 & 88,0 & $-1,0$ & 3,5 \\
\hline 18 & 8,5 & 9,5 & 9,5 & $-1,0$ & $-1,0$ & 96,5 & 94,5 & 94,0 & 2,0 & 2,5 \\
\hline 19 & 9,0 & 12,5 & 12,0 & $-3,5$ & $-3,0$ & 92,5 & 95,0 & 93,0 & $-2,5$ & $-0,5$ \\
\hline 20 & 10,5 & 11,5 & 12,5 & $-1,0$ & $-2,0$ & 83,0 & 84,0 & 83,0 & $-1,0$ & 0 \\
\hline 21 & 13,0 & 15,0 & 13,5 & $-2,0$ & $-0,5$ & 95,5 & 93,0 & 95,0 & 2,5 & 0,5 \\
\hline 22 & 13,5 & 14,0 & 14,5 & $-0,5$ & $-1,0$ & 87,5 & 92,5 & 89,0 & $-5,0$ & $-1,5$ \\
\hline 23 & 15,0 & 17,0 & 15,0 & $-2,0$ & 0,0 & 88,0 & 86,0 & 87,0 & 2,0 & 1,0 \\
\hline Média & 6,39 & 7,87 & 8,50 & $-1,48$ & $-2,11$ & 92,6 & 93,1 & 92,1 & $-0,53$ & 0,46 \\
\hline $\begin{array}{l}\text { Distância } \\
\text { euclidiana }\end{array}$ & $\cdots$ & -- & --- & 9,30 & 11,21 & $\cdots$ & $\cdots$ & -- & 11,26 & 9,52 \\
\hline Teste de $t$ & -- & -- & $--\cdot$ & $5,51^{* *}$ & $9,81^{* *}$ & $\cdots$ & -- & --- & $1,09 \mathrm{NS}$ & $1,13 \mathrm{NS}$ \\
\hline
\end{tabular}

** = Significativo a $1 \%$ de probabilidade; NS = Não Significativo.

raízes. A possibilidade de utilização dos métodos de avaliação no monitor e em papel impresso como alternativa ao método convencional de germinação possui as seguintes vantagens: a) agiliza e facilita as avalições de plântulas na realização do teste de germinação; b) as imagens das plântulas podem ser armazenadas na memória do computador, e analisadas posteriormente, ao passo que no método convencional a leitura tem que ser de imediato; c) juntamente com o boletim de análise existe a possibilidade de se fornecer ao solicitante uma cópia autêntica das sementes analisadas; d) poderá no futuro eliminar a contra amostra mediante regulamentação pelos órgãos competentes; d) embora não tenha sido feito uma análise econômica, ficou bastante evidente que, independentemente do custo inicial de um computador, impressora e "scanner", a agilização das análises poderá, ao longo do tempo, reduzir o custo das mesmas, uma vez que o analista poderá realizar um maior número de análises no mesmo tempo do método convencional, por outro lado podese citar como limitações a dificuldades em não poder observar todos os lados das plântulas e a não possibilidade de ver as profundidades das lesões.

\section{CONCLUSÃO}

A avaliação do dano mecânico em sementes no monitor de computador e em papel impresso proporciona resultados detalhados, e a avaliação de plântulas no monitor e em papel impresso, é viável e reproduz os resultados obtidos do método convencional.

\section{REFERÊNCIAS}

BRASIL. Ministério da Agricultura e da Reforma Agrária. Regras 
para análise de sementes. Brasilia, SNDA/DNDV/CLAV, 1992. $188 p$.

DOTY, J.A.; KENNEDY, A.C. \& PAN, W.L. Rapid bioassay for inhibitory rhizobacteria using digital image analysis. Soil Science Society of America Journal. v.58, n.6, p.1699-1701. 1994.

MARCOS FILHO, J.; CICERO, S.M. \& SILVA, W.R. Testes para avaliação rápida da qualidade das sementes. In: Avaliação da qualidade das sementes. Piracicaba: Fundação de Estudos
Agrários Luiz de Queiroz - FEALQ, 1987. p.204-211.

MORRISON, D.F. Multivariate statistical methods. 2.ed. New York: McGraw-Hill, 1976. $415 p$.

PAN, W.L. \& BOLTON, R.P. Root quantification by edge discrimination using a desktop scanner. Agronomy Journal, Madison. v.83, n.3, p.1047-1052. 1991.

SNEDECOR, G.W. \& COCHRAN, W.G. Méthods estadistics. México: Companhia Editorial Continental, 1974. 703p. 